\title{
AVALIAÇÃO DE PARÂMETROS FISICO-QUÍMICO DE POLPAS CONGELADAS DE GRAVIOLA COMERCIALIZADA EM SUPERMERCADOS DE SÃO LUÍS - MA
}

\author{
PHYSICAL AND CHEMICAL PARAMETERS EVALUATION OF GRAVIOLA FROZEN PULP \\ MARKETED IN SUPERMARKETS OF SÃO LUIS - MA
EVALUACIÓN DE LOS PARÁMETROS FÍSICOS Y QUÍMICOS DE LA PULPA CONGELADA DE GRAVIOLA VENDIDAS EN LOS SUPERMERCADOS DE SÃO LUIS - MA

Romario C. Leal

Valéria $B$. dos Reis

Djavania A. Luz

\begin{abstract}
Resumo: Foi avaliada a qualidade da polpa congelada de graviola comercializada em supermercados de São Luís - MA, através de parâmetros físico-químicos, com a finalidade de verificar a sua adequação às normas e padrões vigentes no país. Os resultados obtidos para a polpa de graviola foram comparados com o P.I.Q. de suco dessa fruta. Os resultados indicaram que as amostras não atenderam ao padrão, conforme legislação vigente, entretanto, continuam sendo uma fonte rica em vitamina C, com até um quarto da recomendação de ingestão diária. No geral, esses resultados indicam a urgência na elaboração dos P.I.Q's para a polpa de graviola, a fim de garantir ao consumidor produtos de qualidade.
\end{abstract}

Palavras-chave: Qualidade. Polpa de fruta congelada. Padrão de Identidade e Qualidade.

\begin{abstract}
The quality of frozen graviola pulp has been evaluated in the supermarkets of São Luís - MA by physical chemical parameters, with the intent to verify its suitability according to the standards specified in the country. The results obtained for the graviola pulp were compared to the Standards of Identity and Quality of this fruit's juice. The results outpointed that the samples did not meet the required standard, according to the country"s law, however, they are still a great source of vitamin C, with recommendation of one fourth of daily intake. In general, those results outpoint the need of an urgent elaboration of the Standards of Identity and Quality for the graviola pulp in order to ensure products of quality to the costumers.
\end{abstract}

Keywords: Quality. Frozen fruit pulp. Quality and Identity Standard.

Resumen: Se evaluó la calidad de la pulpa de graviola congelada vendida en los supermercados de São Luís - MA, a través de parámetros físico-químicos, a fin de verificar su adecuación a las normas y estándares imperantes en el país. Los resultados obtenidos para la pulpa de graviola fueron comparados con el Estándar de Identidad y Calidad (EIC) de zumos de esa fruta. Los resultados indicaron que las muestras no cumplen con el estándar, de acuerdo con la ley actual, pero siguen siendo una fuente rica de vitamina $C$, con hasta un cuarto de la ingesta diaria recomendada. En general, estos resultados indican la urgencia en la elaboración de los EIC's para la pulpa de graviola, a fin de garantizar a los consumidores productos de calidad.

Palabras clave: Calidad. La pulpa de fruta congelada. Estándar de Identidad y Calidad.

\footnotetext{
*Artigo recebido junho 2013
}

Aprovado em junho 2013 


\section{INTRODUÇÃO}

O consumo mundial de frutas tem crescido nos últimos anos a uma taxa média anual de $5,6 \%$. Parte deste crescimento pode ser explicado pela mudança de hábito dos consumidores, os quais cada vez mais procuram nas frutas, a garantia de um alimento saudável e funcional. Segundo a Organização Mundial de Saúde (OMS), o consumo per capita recomendado por ano é de $146 \mathrm{~kg}$ de frutas. No Brasil, este consumo é de apenas $57 \mathrm{~kg}$. É neste cenário que surge o mercado das polpas de frutas, cujas vantagens vão desde a garantia de oferta dos sabores da fruta durante o ano inteiro, passando pela oportunidade de agregação de valor e pelo aproveitamento do excedente de produção das frutas. Além disso, a polpa é de fácil transporte e armazenamento e possui vida de prateleira de aproximadamente um ano, desde que conservada e exposta ao consumo de maneira adequada (MENDES, 2008). A região Nordeste apresenta um bom potencial para produção de polpas de frutas tropicais, dentre estas pode-se destacar a graviola.

A necessidade de diretrizes para a elaboração de Padrões de Identidade e Qualidade (P.I.Q.) para polpa de frutas tropicais congeladas se faz presente em função da atual situação de comercialização do produto, uma vez que se observa uma grande variabilidade no que concerne às características organolépticas: cor, sabor, aroma e textura, que são atributos mais facilmente detectáveis pelo consumidor, além da qualidade sanitária, menos notória ao público e que, em algumas indústrias, deixa muito a desejar.
Segundo o Ministério da Agricultura, polpa de fruta é definida como produto não fermentado, não concentrado, não diluído, obtida pelo esmagamento de frutos polposos, através de um processo tecnológico adequado, com um teor mínimo de sólidos totais provenientes da parte comestível do fruto, específico para cada polpa de fruta (BRASIL, 2001).

O processamento de frutas para obtenção de polpas é uma atividade agroindustrial importante, na medida em que agrega valor econômico à fruta, evitando desperdícios e minimizando perdas que podem ocorrer durante a comercialização do produto in natura. Um fluxograma do processo genérico de obtenção de polpa de fruta está representado pela figura 1.

O objetivo deste trabalho foi avaliar a qualidade físico-química da polpa de graviola comercializadas em supermercados de São Luís/MA, verificando a sua adequação às normas e padrões vigentes no país.

\section{PARTE EXPERIMENTAL}

As amostras das polpas de graviola foram adquiridas em distintos supermercados de São Luis - MA sendo refrigeradas $\left(\approx 4^{\circ} \mathrm{C}\right)$, até posteriores análises. Ressaltando que foram selecionadas 3 (três) marcas mais presentes nos estabelecimentos. As análises físico-químicas foram realizadas seguindo as normas do Instituto Adolfo Lutz (2005).

\subsection{Métodos}

Para todas as determinações analíticas, as polpas de frutas foram descongeladas, homogeneizadas e equilibradas à temperatura ambiente $\left(\approx 25^{\circ} \mathrm{C}\right)$.

Figura 1 - Fluxograma de obtenção de polpa de fruta congelada

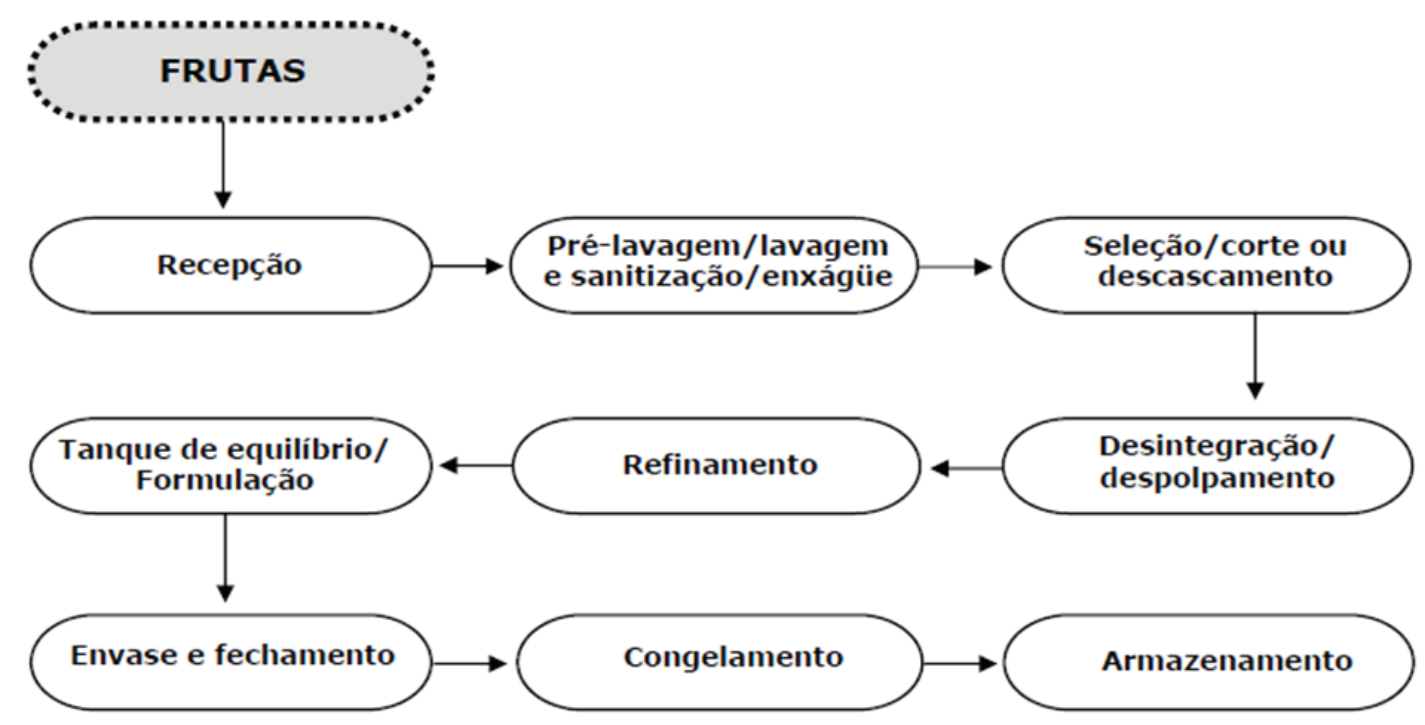

Fonte: Tolentino e Gomes (2008) 
A determinação do $\mathrm{pH}$ foi obtida com o uso do $\mathrm{pHmetro}$ digital (Quimis), que foi aferido à temperatura de $25^{\circ} \mathrm{C}$ e calibrado com soluções tampão pH 4 e 7; o índice de acidez obteve-se por volumetria potenciométrica; o teor de sólidos solúveis por refratometria; sólidos totais foram determinados em estufa à $105^{\circ} \mathrm{C}$; açúcares totais pelo método de Lane-Eynon e vitamina $\mathrm{C}$ por volumetria com iodato de potássio.

\section{RESULTADOS E DISCUSSÃO}

Os valores obtidos nas análises para avaliar o perfil da qualidade das polpas de graviola, através dos parâmetros físico-químicos, estão representados na tabela 1.

Observando-se a tabela 1, percebe-se que todas as amostras analisadas, com relação aos valores de $\mathrm{pH}$, encontram-se fora dos padrões de identidade e qualidade (PIQ) estabelecidos, pois as amostras apresentaram valores de 3,39 a 3,47 e o PIQ estabelece valor mínimo de 3,50. No entanto, em estudos feitos por Sacramento et al. (2003) e Caldas et al. (2006), referentes ao mesmo tipo de análise para espécies de graviola in natura, foram encontrados valores de $\mathrm{pH}$ similares aos encontrados por este trabalho. Supõe-se que a acidez observada deva estar correlacionada diretamente a fatores externos (clima, solo, tempo de maturação, etc.) da própria fruta, contribuindo para valores exclusivos para cada espécie, além de uma provável não correção deste item durante o processamento da polpa.

Na determinação de sólidos solúveis, constatou-se que apenas a amostra $\mathrm{C}$ com $7,4^{\circ} \mathrm{Brix}$ apresentou resultado inferior ao estabelecido pela legislação vigente. E em estudos similares, Silva, Oliveira e Jales (2006) obtiveram $3,2^{\circ}$ Brix em suas análises, um valor inferior ao encontrado neste estudo. Segundo Bueno et al. (2002), isso pode ter sido ocasionado por adição de água nas polpas, ou então, as frutas foram colhidas em período de chuva, o que promoveria a diluição dos sólidos solúveis. Já as demais amostras (A e B) com 10,6 e $10,4^{\circ}$ Brix, respectivamente, apresentaram valores acima do mínimo exigido, estando, portanto de acordo com PIQ.

Considerando os resultados de índice de acidez obtidos e a Legislação em vigor, todas as amostras apresentaram-se dentro dos padrões, uma vez que o PIQ estabelece apenas valor mínimo de 0,60\%. As amostras $\mathrm{A}$ e $\mathrm{B}$ foram as que apresentaram os maiores valores de acidez com 1,29\% e 1,23\%, respectivamente, valores próximos aos encontrados por Caldas et al. (2006), que encontrou em suas análises valores médios de $1,39 \%$. No entanto, a amostra C, com 0,90\% de acidez total, aproximou-se dos valores médios encontrados por Sacramento et al. (2003), que obteve $1 \%$ de acidez para frutas in natura. Esses altos valores estão ligados diretamente ao grau de maturação da fruta, uma vez que o teor de ácido cítrico diminui com o amadurecimento da mesma, segundo Salgado, Guerra e Melo Neto (1999).

Quanto ao teor de vitamina $\mathrm{C}$, todas as amostras encontram-se acima do valor mínimo estabelecido pelo PIQ, sendo que a amostra B foi a que apresentou maior teor com $23,47 \mathrm{mg}$ de ácido ascórbico pra cada $100 \mathrm{~g}$ de polpa, seguido pela amostra A com 21,52 mg/100 g e $16,62 \mathrm{mg} / 100 \mathrm{~g}$ da amostra C, mostrando-se distante dos resultados obtidos por Silva, Oliveira e Jales (2006) no estudo da fruta in natura, com $91 \mathrm{mg} / 100 \mathrm{~g}$, e bem acima dos $3,50 \mathrm{mg} / 100 \mathrm{~g}$ obtidos por Caldas et al. (2006) em polpas de graviola congeladas. Essa diferença pode ser atribuída às condições de produção e ao armazenamento das polpas nos supermercados, uma vez que a vitamina $C$ sofre decomposição em presença de luz e variação de temperatura, segundo Teixeira e Monteiro (2006).

Para as análises de sólidos totais, apenas na amostra A se obteve um valor de $12,04 \mathrm{~g}$ de resíduo seco, encontrando-se acima do valor

Tabela 1 - Avaliação do perfil da qualidade das polpas de graviola

\begin{tabular}{c|c|c|c|c|c}
\hline $\begin{array}{c}\text { Características } \\
\text { físico-químicas }\end{array}$ & Amostra A & Amostra B & Amostra C & \multicolumn{2}{|c}{ MIQ $^{*}$} \\
\hline $\mathbf{p H}$ & 3,39 & 3,43 & 3,47 & 3,50 & --- \\
\hline Sólidos solúveis ( ${ }^{\circ}$ Brix) & 10,6 & 10,4 & 7,4 & 9,00 & --- \\
\hline Índice de acidez (\%) & 1,29 & 1,23 & 0,90 & 0,60 & --- \\
\hline Vitamina C (mg/100g) & 21,52 & 23,47 & 16,62 & 10,00 & -- \\
\hline Sólidos totais (g/100g) & 12,04 & 11,54 & 6,88 & 12,00 & -- \\
\hline Açúcares totais (g/100g) & 7,00 & 6,43 & 4,72 & 6,50 & 17,00 \\
\hline
\end{tabular}

*Padrões de Identidade e Qualidade

Fonte: Dados elaborados pelos autores 
mínimo estabelecido pela norma vigente. O PIQ define como valor mínino $12 \mathrm{~g}$ de sólidos totais a cada $100 \mathrm{~g}$ de polpa. A amostra C foi a que apresentou menor massa de resíduos, apenas $6,88 \mathrm{~g} / 100 \mathrm{~g}$, e na amostra B o obteve-se $11,54 \mathrm{~g} / 100 \mathrm{~g}$ da polpa. Essa diminuição de sólidos totais nas polpas congeladas diz respeito à quantidade de água que possivelmente foi adicionada na fabricação para facilitar as operações unitárias de trituração e despolpamento da fruta, segundo Caldas et al. (2006).

Na determinação de açúcares totais apenas a amostra A encontra-se de acordo com a norma em vigor, uma vez que esta apresentou $7 \mathrm{~g} / 100 \mathrm{~g}$ e o PIQ determina como valores 6,50 $\mathrm{g} / 100 \mathrm{~g}$ (mínimo) e de $17 \mathrm{~g} / 100 \mathrm{~g}$ (máximo). A amostra B apresentou valor próximo ao mínimo determinado pelo PIQ com 6,43 g/100 $\mathrm{g}$, já a amostra $\mathrm{C}$ apresentou teor de açúcares totais bem inferiores às outras duas marcas com apenas $4,72 \mathrm{~g} / 100 \mathrm{~g}$. Vale ressaltar que Salgado, Guerra e Melo Filho (1999), em seus estudos sobre polpas congeladas de graviola, encontrou valores médios de $9,50 \mathrm{~g} / 100 \mathrm{~g}$. No entanto, Sacramento et al. (2003) encontrou valores médios de 13,31 g/100 g para polpas de graviola in natura. Supõe-se que tal discrepância se dê em razão da época de colheita, maturação e armazenamento dos frutos, antes do processamento, além do acondicionamento das polpas nos supermercados.

Sugere-se, para melhoria da qualidade do produto, um maior rigor na escolha dos fornecedores; seleção criteriosa da matéria prima, de modo que apresentem homogeneidade com relação aos diversos parâmetros de qualidade; processamento imediato dos frutos; utilização de congelamento rápido e mão de obra qualificada na produção, além do uso de vestuário adequado e, finalmente a aplicação do Sistema de Análise de Perigos e Pontos Críticos de Controle (APPCC) e a adoção das Boas Práticas de Fabricação (BPF) como forma de garantir a qualidade do produto.

\section{CONSIDERAÇÕES FINAIS}

De acordo com a Instrução Normativa no 01 , de 7 de janeiro de 2000, que estabelece os padrões de identidade e as características mínimas de qualidade gerais para polpas de fruta, concluiu-se que nenhuma das amostras coletadas apresentaram-se completamente dentro dos padrões de qualidade estabelecido (BRASIL, 2000). Estes resultados são preocupantes, servindo de alerta para que se agilize a normatização desse produto, ao mesmo tempo em que reflete a real situação desse segmento da Agroindústria, que necessita padronizar, além do produto, também o processo tecnológico para obtenção de uma polpa com qualidade, a fim de possibilitar a conquista de novos mercados, sintonizados com as demandas e preferências de um consumidor cada dia mais exigente.

\section{REFERÊNCIAS}

ARAÚJO, J. L.; QUEIROZ, A. J. M.; FIGUEIREDO, R. M. F. Propriedades termofísicas da polpa do cupuaçú com diferentes teores de sólidos. Ciência Agrotécnica, Lavras, v.28, n.1, p.126134, jan./fev., 2004.

BRASIL. Instrução normativa ${ }^{\circ} 1$, de 7 de janeiro de 2000. Brasília, DF, 2000. Dísponivel em: <www.saa.rs.gov.br/.../126989581629.03 enol_in_1_00_mapa.doc>. Acesso em: 18 jan. 2012.

BRASIL. Resolução RDC n. 12, de 02 de janeiro de 2001, da Agência Nacional de Vigilância Sanitária. Diário Oficial da República Federativa do Brasil, Brasília, DF, 10 jan. 2001. Seção 1, p.45-53.

BUENO, S. M. R. V. et al. Avaliação da qualidade de polpas de frutas congeladas. Revista Instituto Adolfo Lutz, São Paulo, v. 62, n. 2, p. 121-126, 2002.

CALDAS, Z. T. C. et al. Avaliação de qualidade de polpas de frutas comercializadas no Estado do Rio Grande do Norte. 2006. In: JORNADA NACIONAL DA AGROINDÚSTRIA, 1., 2006, Bananeiras. Anais... Bananeiras: UFPB, 2006.

CID, C.; ASTICISARARAN, I.; YBELLU, J. Modificaciones em el contenido de vitamina $\mathrm{C}$ em zumos naturales desde su elaboración hasta su posible consumo. Alimentaria, Madrid, v.28, p.41-43, 1991.

EVANGELISTA, J. Tecnologia de alimentos. 2 ed. Rio de Janeiro: Livraria Atheneu Editora,1992.

INSTITUTO ADOLFO LUTZ. Normas analíticas do Instituto Adolfo Lutz. São Paulo, 2005, v. 1.

MENDES, P. A. M. Avaliação dos parâmetros físico-químicos determinados nos certificados oficiais de análise das polpas de frutas com padrões de identidade e qualidade. 2008. Dissertação (Mestrado em Ciências Agrárias) - Faculdade de Agranomia e Medicina Veterinária, Universidade de Brasília, Brasília, DF, 2008.

SACRAMENTO, C. K. et al. Caracterização física e química de frutos de três tipos de Gravioleira (annona muricata I.). Revista Brasileira de Fruticultura, Jaboticabal, v. 25, n. 2, p. 329-331, ago. 2003.

SALGADO, S. M.; GUERRA, N. B. ; MELO FILHO, A. B. Polpa de fruta congelada: efeito do processamento sobre o conteúdo de fibra alimentar. Revista de Nutrição, Campinas, v. 12, n. 3, p. 303-308, set./dez., 1999.

SEBRAE/MG. A agroindústria de frutas, 2004. Disponível em <www.sebraemg.com.br/agronegocios/Fruticultura/Cap5.doc>. Acesso em 20 nov. 2012. 
Romario C. Leal, Valéria B. dos Reis, Djavania A. Luz.

SILVA, M. T. M.; OLIVEIRA, J. S.; JALES, K. A.. Avaliação da qualidade físico-química de polpas de frutas congeladas comercializadas no interior do ceará. Ciência e Tecnologia de Alimentos, Campinas, set./dez. de 2006.

TEIXEIRA, M.; MONTEIRO, M. Degradação da vitamina $\mathrm{C}$ em suco de frutas. Alimentos e $\mathrm{Nu}$ trição, Araraquara. v.17, n.2, p.219-227, abr./ jun. 2006.
TOlentino, V. R.; GOMES, A. Processamento de Vegetais: frutas/polpa congelada. Niterói, Programa Rio Rural, 2008.

YAHIA, E. M. The contribution of fruit and vegetable consumption to human health. In: ROSA, L. A.; ALVAREZ-PARRILLA, E.; GONZALEZ-AGUILARA; G. A. Fruit and vegetable phytochemicals: chemistry, nutritional value and stability. Hoboken: Wiley-Blackwell, 2010. p. 3-51. 